\title{
Detection of $A B C C 1$ expression in classical Hodgkin lymphoma is associated with increased risk of treatment failure using standard chemotherapy protocols
}

Wesley Greaves ${ }^{1}$, Lianchun Xiao², Beatriz Sanchez-Espiridion' ${ }^{1}$ Kranthi Kunkalla', Kunal S Dave', Cynthia S Liang ${ }^{1}$, Rajesh R Singh ${ }^{1}$, Anas Younes ${ }^{3}, \mathrm{~L}$ Jeffrey Medeiros ${ }^{1}$ and Francisco Vega ${ }^{1 *}$

\begin{abstract}
Background: The mechanisms responsible for chemoresistance in patients with refractory classical Hodgkin lymphoma $(\mathrm{CHL})$ are unknown. ATP-binding cassette $(\mathrm{ABC})$ transporters confer multidrug resistance in various cancers and $A B C C 1$ overexpression has been shown to contribute to drug resistance in the $\mathrm{CHL}$ cell line, $\mathrm{KMH} 2$.

Findings: We analyzed for expression of five $A B C$ transporters $A B C B 1, A B C C 1, A B C C 2, A B C C 3$ and $A B C G 2$ using immunohistochemistry in 103 pre-treatment tumor specimens obtained from patients with CHL. All patients received first-line standard chemotherapy with doxorubicin $\left(\right.$ Adriamycin $\left.{ }^{\circledR}\right)$, bleomycin, vinblastine, and dacarbazine (ABVD) or equivalent regimens. ABCC1 was expressed in Hodgkin and Reed-Sternberg (HRS) cells in 16 of 82 cases (19.5\%) and ABCG2 was expressed by HRS cells in 25 of 77 cases (32.5\%). All tumors were negative for ABCB1, $A B C C 2$ and $A B C C 3$. ABCC1 expression was associated with refractory disease $(p=0.01)$ and was marginally associated with poorer failure-free survival $(p=0.06)$. Multivariate analysis after adjusting for hemoglobin and albumin levels and age showed that patients with CHL with HRS cells positive for ABCC1 had a higher risk of not responding to treatment $(\mathrm{HR}=2.84,95 \%, \mathrm{Cl}: 1.12-7.19 \mathrm{p}=0.028)$.
\end{abstract}

Conclusions: Expression of ABCC1 by HRS cells in CHL patients predicts a higher risk of treatment failure and is marginally associated with poorer failure-free survival using standard frontline chemotherapy regimens.

Keywords: Classical Hodgkin lymphoma, ABCC1, ATP binding cassettes, Immunohistochemistry

\section{Background}

Classical Hodgkin lymphoma (CHL) is largely a curable disease using the widely accepted current standard firstline chemotherapy regimen of doxorubicin (Adriamycin ${ }^{\circledR}$ ), bleomycin, vinblastine, and dacarbazine (ABVD) or equivalent regimens, with or without consolidation radiotherapy [1]. However, approximately $20 \%$ of patients with CHL do not respond following first-line therapy, or relapse quickly, and require additional treatment with salvage chemotherapy with or without stem cell transplantation [1,2]. A drawback to the currently used

\footnotetext{
* Correspondence: fvegava@mdanderson.org

${ }^{1}$ Department of Hematopathology, Unit 72, The University of Texas MD

Anderson Cancer Center, 1515 Holcombe Boulevard, Houston, TX 77030, USA Full list of author information is available at the end of the article
}

treatment modalities is their association with potentially life-threatening toxicities. In addition, patients cured of CHL have an increased lifetime relative risk of death from non CHL-related causes, presumably attributable, at least in part, to therapy [3]. Thus, investigators continue to actively pursue novel prognostic biomarkers and therapeutic options in CHL patients with the goals of maintaining or improving survival rates as well as minimizing adverse side effects in patients with favorable prognosis [2]. Recently, a number of biomarkers expressed by Hodgkin and Reed-Sternberg (HRS) cells as assessed in tissue samples have been proposed as being useful for predicting prognosis in CHL patients [4]. These molecules include matrix metalloproteinase 11 (MMP11), CD20, Bcl2, MAL, HLA class II and Ki67, 
as well as cells within the CHL microenvironment, such as tumor-associated macrophages or subsets of tumor-infiltrating lymphocytes, including FOXP3+ regulatory $\mathrm{T}$ cells (Tregs) and granzyme $\mathrm{B}+\mathrm{T} / \mathrm{NK}$ cells [5-10].

The development of chemotherapy resistance by cancer cells is multifactorial [11]. ATP binding cassette (ABC) transporters comprise a ubiquitous family of transmembrane proteins that play a physiologic role in the transport of substrates across cytoplasmic membranes. $\mathrm{ABC}$ transporters also play a role in multidrug resistance (MDR) in multiple tumor types by using ATP as an energy source to actively expel drug substrates from the tumor cell cytoplasm into the extracellular space [12]. Expression of $A B C$ transporters has been shown to correlate with response to therapy and prognosis in several hematological malignancies including acute myeloid leukemia and diffuse large B-cell lymphoma [13-15]. Although the clinical impact of ABC transporters in CHL has not been reported, several drugs used to treat $\mathrm{CHL}$ are known substrates of various $\mathrm{ABC}$ transporters [11,16], including doxorubicin (a substrate for $\mathrm{ABCB} 1, \mathrm{ABCC} 1, \mathrm{ABCC} 2, \mathrm{ABCC} 3, \mathrm{ABCG}$ ), vinblastine (a substrate for $\mathrm{ABCB} 1$ and $\mathrm{ABCC} 1$ ) and vincristine (a substrate for $\mathrm{ABCC} 1$ ).

Steidl et al. recently showed overexpression of the $\mathrm{ABC}$ transporter, $\mathrm{ABCC} 1$ (also known as multidrug resistance protein 1 - MRP1) in the therapy-resistant CHL-derived cell line, KMH2 [17]. They further showed that increased sensitivity of $\mathrm{KMH} 2$ cells to Adriamycin ${ }^{\circledR}$ toxicity by siRNA silencing of $A B C C 1$. Prompted by this finding, we assessed for expression of five $\mathrm{ABC}$ transporters, $\mathrm{ABCG} 2, \mathrm{ABCB} 1, \mathrm{ABCC} 1, \mathrm{ABCC} 2$, and $\mathrm{ABCC} 3$, in untreated $\mathrm{CHL}$ tumor specimens. We also investigated the potential prognostic value of expression of these $\mathrm{ABC}$ transporters in $\mathrm{CHL}$.

\section{Design and methods}

The overall clinical and pathologic features of the study group are summarized in Table 1 . The group included 103 patients with CHL who were seen at our hospital and treated with standard front-line chemotherapy using ABVD (36 patients) or equivalent regimens including CVPP/ABDIC (cyclophosphamide, vinblastine, procarbazine, and prednisone/Adriamycin ${ }^{\circledR}$, bleomycin, dacarbazine, lomustine and prednisone) (20 patients), MOPP/ ABVD (mechlorethamine, vincristine, prednisone, procarbazine/Adriamycin ${ }^{\circledR}$, bleomycin, vinblastine, dacarbazine) (3 patients) or NOVP (Novantrone ${ }^{\circledR}$, vincristine, vinblastine, and prednisone) (44 patients) with and without radiotherapy. Additionally, 10 patients underwent allogeneic stem cell transplantation as salvage therapy. We analyzed for expression of five $A B C$ transporters $\mathrm{ABCG} 2, \mathrm{ABCB} 1, \mathrm{ABCC} 1, \mathrm{ABCC} 2$, and $\mathrm{ABCC} 3$ - in pre-
Table 1 Selected demographic and histologic features of $103 \mathrm{CHL}$ patients

\begin{tabular}{lc}
\hline Parameter & $\mathbf{n}(\%)$ \\
\hline Gender & $59(57.3 \%)$ \\
Male & $44(42.7 \%)$ \\
Female & 36 years (range: 13-85) \\
Mean age & $28(27 \%)$ \\
Age $\geq 45$ years & \\
Ann Arbor Stage & $9(8.7 \%)$ \\
I & $48(46.6 \%)$ \\
II & $26(25.2 \%)$ \\
III & $20(19.4 \%)$ \\
IPS & \\
$<3$ & $83(80.6 \%)$ \\
$\geq 3$ & $20(19.4 \%)$ \\
Radiotherapy & \\
No & $21(22.6 \%)$ \\
Yes & $72(77.4 \%)$ \\
Chemotherapy & \\
ABVD & $35(72.8 \%)$ \\
ABVD + rituximab & $22(21.3 \%)$ \\
CVPP/ABDIC & $3(2.9 \%)$ \\
MOPP/ABVD & $3(2.9 \%)$ \\
NOVP & \\
Nodular sclerosis & $20(19.4 \%)$ \\
Mixed cellularity & $34(42.7 \%)$ \\
\hline
\end{tabular}

treatment samples of CHL using (see Table 2). immunohistochemical methods and tissue microarrays (TMA). Seven TMAs were constructed using triplicate cores prepared from routinely processed paraffin-embedded tissue specimens as described previously [18]. Additionally, we were able to retrieve tissue blocks and use routine histologic sections to analyze ABCC1 and ABCG2 expression in 13 and 5 CHL tumors, respectively, that suffered tissue loss on the TMAs. This work was performed under an approved IRB protocol in our institution. For each marker, a tumor was considered positive when HRS cells were positive. For these proteins expression was all or none. In other words, in positive cases virtually all HRS cells were positive.

Fisher's exact test was used to evaluate the association of clinical response with categorical variables. The Kaplan-Meier method and log rank test were used for survival analysis. The following variables were evaluated in univariate analysis: disease stage (IV vs. I/II/III), 
Table 2 Antibodies used for immunohistochemistry

\begin{tabular}{llllll}
\hline $\begin{array}{l}\text { Antibody } \\
\text { Common Name }\end{array}$ & Systematic Name & Clone & Manufacturer & Antibody Conc. & $\begin{array}{c}\text { Normal Tissue } \\
\text { Control }\end{array}$ \\
\hline ABCG2 & MXR, BCRP, ABC-P & Mouse monoclonal BXP-21 & $\begin{array}{l}\text { Santa Cruz Biotechnology Inc. } \\
\text { Santa Cruz, CA }\end{array}$ & $1: 40$ & Placenta \\
MDR1 & ABCB1, PGP & Mouse monoclonal G-1 & $\begin{array}{l}\text { Santa Cruz Biotechnology Inc. } \\
\text { Santa Cruz, CA }\end{array}$ & 1:100 & Liver \\
MRP1 & ABCC1 & Mouse monoclonal QCRL-1 & $\begin{array}{l}\text { Santa Cruz Biotechnology Inc. } \\
\text { Santa Cruz, CA }\end{array}$ & Stomach \\
MRP2 & ABCC2 & Mouse monoclonal M2 III-6 & Abcam Inc. Cambridge MA & $1: 50$ & Liver \\
MRP3 & ABCC3 & Mouse monoclonal DTX1 & Abcam Inc. Cambridge MA & $1: 50$ & Liver \\
\hline
\end{tabular}

chemotherapy (ABVD, CVP or NOVP), radiation therapy (yes and no), bone marrow metastasis (positive and negative), serum albumin $(<$ and $>40 \mathrm{~g} / \mathrm{L})$, WBC ( $<$ and $\geq 15,000$ per $\left.\mathrm{mm}^{3}\right)$, hemoglobin $(<$ or $>105 \mathrm{~g} / \mathrm{L})$, lymphocytes $\left(<\right.$ and $\geq 600$ per $\mathrm{mm}^{3}$ or $<$ and $\geq 8 \%$ of WBC), gender, International Prognostic Score (IPS) $(<$ and $\geq 3)$, and age $(<$ and $\geq 45$ years). Multivariate Cox proportional hazards models including variables with $\mathrm{p}$ value $<0.15$ in univariate analysis were fitted to evaluate the association of survival with demographic and clinical factors. Variables with $\mathrm{p}$ values $<0.05$ were considered statistically significant. S plus software 8.04 (TIBCO software Inc., Palo Alto, CA) and SAS software (SAS Institute Inc., Cary, NC) were used for statistical analysis.

\section{Results and discussion}

We tested for expression of five $\mathrm{ABC}$ transporters in untreated tumor specimens of CHL. These transporters use as substrates chemotherapeutic agents commonly used to treat $\mathrm{CHL}$ patients including Adriamycin ${ }^{\circledR}$, vincristine, vinblastine, and mitoxantrone, among others [11].
ABCG2 and ABCC1 were expressed by HRS cells in a subset of CHL tumors (Figure 1). Sixteen of 82 (19.5\%) CHL were positive for $\mathrm{ABCC} 1$ and 25 of 77 (32.5\%) CHL were positive for ABCG2 (a subset of tissue cores was variably lost on the TMAs). Both ABCC1 and ABCG2 showed cytoplasmic expression in all HRS cells (Figures $1 \mathrm{C}$ and F). There was no substantial difference in the intensity of expression of $\mathrm{ABCC} 1$ or ABCG2 by HRS cells. Variable, non-specific staining for $\mathrm{ABCC} 1$ and ABCG2 was also observed inconsistently in a small subset of background inflammatory cells, including plasma cells, lymphocytes, eosinophils and histiocytes, in both HRS-positive and HRS-negative cases. There was no expression of $A B C B 1, A B C C 2$ and $A B C C 3$ by HRS cells in any case analyzed (Figures $2 \mathrm{~B}, \mathrm{D}$ and $\mathrm{E}$ ). Consistent expression of both $\mathrm{ABCC} 1$ and $\mathrm{ABCG} 2$ in endothelial cells was used as an internal positive control for immunohistochemical staining (see Figures $2 \mathrm{~B}$ and D).

We sought to determine if there was an association between expression of either ABCC1 or ABCG2 and clinical endpoints, such as response to treatment (refractory disease vs non-refractory disease), overall survival

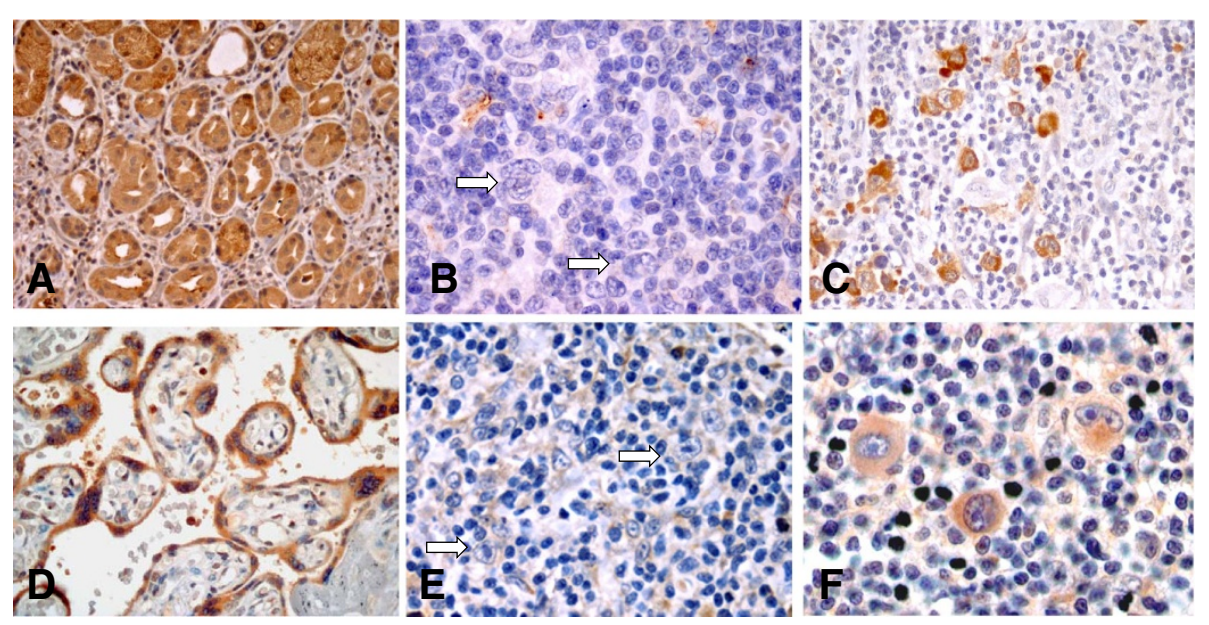

Figure 1 Immunohistochemical expression of $A B C$ proteins in positive controls and CHL tumors. A. ABCC1 is expressed by gastric glands (positive control). B. CHL with negative expression of ABCC1 by HRS cells; scattered histiocytes are weakly positive. C. CHL with HRS cells positive for cytoplasmic expression of ABCC1. D. Placenta with ABCG2 expression in trophoblastic cells (positive control). E. CHL with HRS cells negative for ABCG2; endothelial cells and scattered inflammatory cells are positive. F. CHL with HRS cells positive for cytoplasmic expression of ABCG2. 


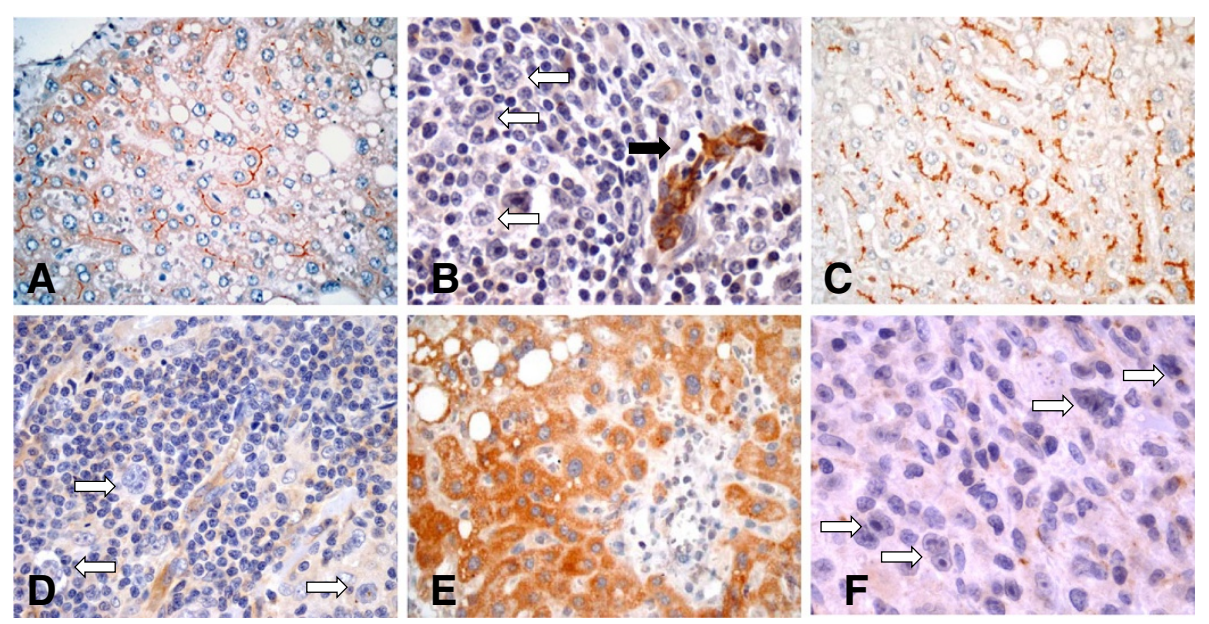

Figure 2 Immunohistochemical expression of ABC proteins in positive controls and call tumors. A. Canalicular staining pattern of MDR1 in liver (positive control). B. MDR1 is not expressed in the HRS cells of CHL (white arrows); endothelial cells are positive (black arrow). C. Canalicular staining pattern of ABCC2 in liver (positive control). D. HRS cells are negative for ABCC2; endothelial cells and scattered lymphocytes are positive. E. Hepatocytes show cytoplasmic expression of ABCC3 (positive control). F. HRS cells are negative for ABCC3.

(OS), and failure free survival (FFS). Admittedly, the numbers are relatively small hampering this analysis. In this study FFS was defined as lack of disease progression, recurrence or death. Refractory disease was defined as patients with only a partial response to therapy, or recurrence within the first 18 months of initial therapy $[19,20]$. The log rank test showed that ABCC1 expression was marginally associated with FFS: 19 of 66 $\mathrm{ABCC} 1$ negative patients and 7 of the $\mathrm{ABCC} 1$ positive patients experienced treatment failure. The estimated 5year FFS probabilities were 80.7\% (95\% CI:71.4\% -91.2\%) for ABCC1 negative group and 68.8\% (95\% CI:49.4\%$95.7 \%)$ for the $\mathrm{ABCC} 1$ positive group, respectively $(\mathrm{p}=0.06$, Figure 3). Multivariate analysis after adjusting for the effects of age, hemoglobin level, and albumin level suggested that $\mathrm{ABCC} 1$ expression was an independent prognostic marker for FFS. Patients with $\mathrm{ABCC} 1$ expression had a higher risk of treatment failure than patients without $\mathrm{ABCC} 1$ expression $(\mathrm{HR}=2.88$, 95\% CI: 1.18-7.01, $\mathrm{p}=0.02$, Table 3). Fisher's exact test suggested that $A B C C 1$ expression was also associated with initial response to treatment (primary refractory $v s$ non-primary refractory). Six of 16 patients (37.5\%) with $\mathrm{ABCC} 1$ expression versus 6 of 66 patients (9.1\%) without $A B C C 1$ expression were primary refractory $(p=0.01)$. This finding supports the results of Steidl and colleagues in the KMH2 cell line [17] and suggests that expression of $\mathrm{ABCC} 1$ may contribute to primary drug resistance in CHL. Three of 16 patients with $\mathrm{ABCC} 1$ positive tumors and 11 of 66 patients with $\mathrm{ABCC} 1$ negative tumors died,

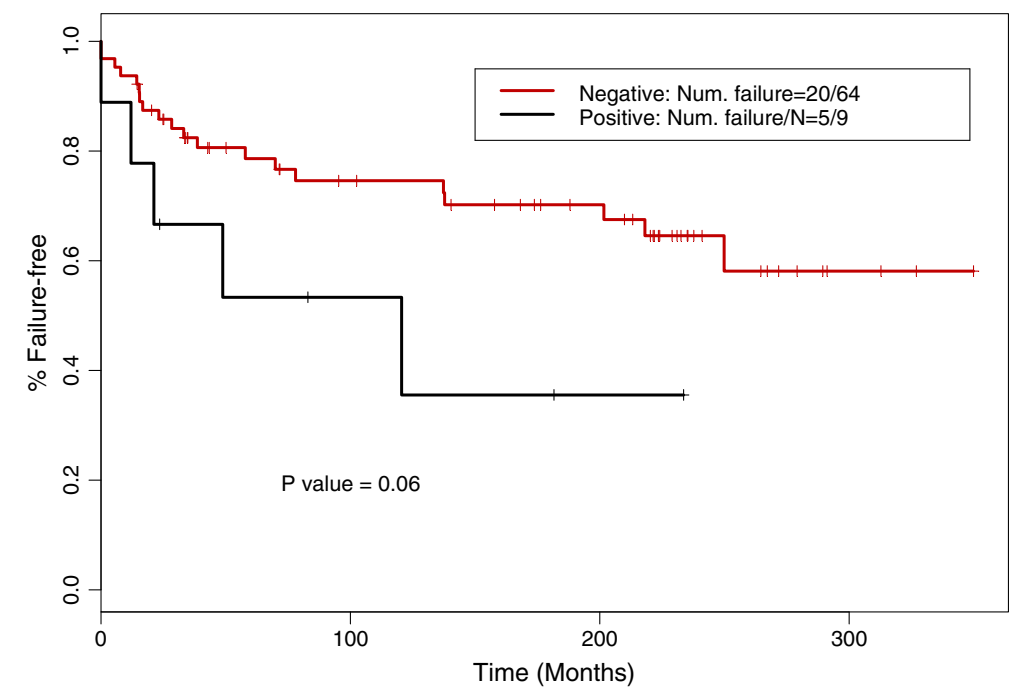

Figure 3 ABCC1 expression was marginally associated with failure-free survival $(p=0.06)$. 
Table 3 Multivariate analysis to evaluate the association between FFS and ABCC1

\begin{tabular}{llll}
\hline & & HR $(\mathbf{9 5} \%$ Cl $)$ & P value \\
\hline ABCC1 & Positive vs. negative & $2.84(1.12,7.19)$ & 0.028 \\
Albumin & $<4$ vs. $>4$ & $1.59(0.70,3.63)$ & 0.27 \\
Age & $>=45$ vs. $<45$ & $2.14(1.53,0.13)$ & 0.13
\end{tabular}

*Please note: $\mathrm{HB}(<10.5$ vs. $>10.5)$ was included in the model as a stratification factor since the proportional hazards assumption for it was not held.

no significant difference was detected in OS between the $A B C C 1$ positive and negative groups $(p=0.74)$. $A B C C 1$ expression was not significantly associated with other clinical parameters (Table 4). Fisher's exact test was also used to compare the patient characteristics between $\mathrm{ABCC} 1$ known and $\mathrm{ABCC} 1$ unknown groups (Additional file 1: Table S1). More patients 45 years of age or older had ABCC1 measurements (17/28, 60.7\%) ( $\mathrm{p}$ value $=0.0036$ ). A majority of patients who received CVPP treatment had ABCC1 measurements $(18 / 20$, $90 \%)(\mathrm{p}$ value $=0.049)$. No other significant difference was detected.
Expression of ABCG2 by HRS cells was not significantly associated with OS, FFS or initial response to treatment. The lack of association of ABCG2 expression with treatment refractoriness, in contrast to $\mathrm{ABCC} 1$, is not fully explained, and relatively little is known about the differential substrate profiles of these two proteins. However, some authors have shown that certain drugs that are poor $\mathrm{ABCC} 1$ substrates, such as mitoxantrone (a type 2 topoisomerase inhibitor), are associated with overexpression of ABCG2 in vitro [11,21], and such differences may have played a role in the discordant impact of these two proteins on therapy resistance in this patient cohort.

\section{Conclusions}

In summary, $\mathrm{ABCC} 1$ and $\mathrm{ABCG} 2$ are expressed by HRS cells in a subset of CHL tumors. Univariate and multivariate analyses showed that expression of $\mathrm{ABCC} 1$ by HRS cells is associated with an increased risk of tumor progression, treatment resistance or death in CHL patients. Our findings corroborate those published by

Table 4 Fisher's exact test to evaluate the association between ABCC1 and other clinical factors

\begin{tabular}{|c|c|c|c|c|}
\hline Covariate & Score & ABCC1 Negative & ABCC1 Positive & Fisher's ExactTest (2-Tail) \\
\hline \multirow[t]{2}{*}{$\overline{A B C G 2}$} & Negative & $39(79.6 \%)$ & $10(20.4 \%)$ & .5227 \\
\hline & Positive & $22(88 \%)$ & $3(12 \%)$ & \\
\hline \multirow[t]{3}{*}{ Chemotherapy } & ABVD (R-ABVD \& MOPP/ABVD) & $20(76.9 \%)$ & $6(23.1 \%)$ & .8762 \\
\hline & CVPP/ABDIC & $15(83.3 \%)$ & $3(16.7 \%)$ & \\
\hline & NOVP & $31(81.6 \%)$ & $7(18.4 \%)$ & \\
\hline \multirow[t]{2}{*}{ Radiotherapy } & No & $17(89.5 \%)$ & $2(10.5 \%)$ & .3329 \\
\hline & Yes & $45(77.6 \%)$ & $13(22.4 \%)$ & \\
\hline \multirow[t]{2}{*}{ Bone marrow disease } & No & $62(79.5 \%)$ & $16(20.5 \%)$ & 1.000 \\
\hline & Yes & $3(100 \%)$ & $0(0 \%)$ & \\
\hline \multirow[t]{2}{*}{ Stage IV disease } & No & $53(80.3 \%)$ & $13(19.7 \%)$ & 1.000 \\
\hline & Yes & $13(81.3 \%)$ & $3(18.8 \%)$ & \\
\hline \multirow[t]{2}{*}{ Hemoglobin } & $\geq 105 \mathrm{~g} / \mathrm{l}$ & $58(79.5 \%)$ & $15(20.5 \%)$ & .6811 \\
\hline & $<105 \mathrm{~g} / \mathrm{l}$ & $8(88.9 \%)$ & $1(11.1 \%)$ & \\
\hline \multirow[t]{2}{*}{ Albumin } & $\geq 40 \mathrm{~g} / \mathrm{l}$ & $35(79.5 \%)$ & $9(20.5 \%)$ & 1.000 \\
\hline & $<40 \mathrm{~g} / \mathrm{l}$ & $23(82.1 \%)$ & $5(17.9 \%)$ & \\
\hline \multirow[t]{2}{*}{ WBC } & $<15,000$ per $\mathrm{mm}^{3}$ & $62(79.5 \%)$ & $16(20.5 \%)$ & .5814 \\
\hline & $\geq 15,000$ per $\mathrm{mm}^{3}$ & $4(100 \%)$ & $0(0 \%)$ & \\
\hline \multirow[t]{2}{*}{ Lymphocytes } & $<600$ per $\mathrm{mm}^{3}$ & $52(80 \%)$ & $13(20 \%)$ & 1.000 \\
\hline & $\geq 600$ per $\mathrm{mm}^{3}$ & $11(78.6 \%)$ & $3(21.4 \%)$ & \\
\hline \multirow[t]{2}{*}{ Age $\geq 45$} & $<45$ years & 51 (78.5\%) & $14(21.5 \%)$ & .5028 \\
\hline & $\geq 45$ years & 15 (88.2\%) & $2(11.8 \%)$ & \\
\hline \multirow[t]{2}{*}{ Sex } & Female & $26(76.5 \%)$ & $8(23.5 \%)$ & .5731 \\
\hline & Male & $40(83.3 \%)$ & $8(16.7 \%)$ & \\
\hline \multirow[t]{2}{*}{ IPS } & $<3$ & $51(77.3 \%)$ & $15(22.7 \%)$ & .2811 \\
\hline & $\geq 3$ & 14 (93.3\%) & $1(6.7 \%)$ & \\
\hline
\end{tabular}


Steidl and colleagues [17] in the KMH2 cell line and provide evidence that expression of $\mathrm{ABCC} 1$ may be useful as an indicator of poorer FFS or failure to respond to therapy in CHL patients who are treated with standard regimens. Additionally, $\mathrm{ABCC} 1$ may serve as a potential target for therapeutic intervention by increasing susceptibility to chemotherapy.

\section{Additional file}

Additional file 1: Table S1. Fisher's exact test to compare clinical factors between $A B C C 1$ unknown and $A B C C 1$ known groups.

\section{Abbreviations}

CHL: Classical Hodgkin lymphoma; ABVD: Adriamycin, bleomycin, vinblastine, and dacarbazine; HRS: Hodgkin Reed-Sternberg cells; MMP11: Matrix metalloproteinase 11; ABC: ATP binding cassette; MDR: Multidrug resistance; CVPP: Cyclophosphamide, vinblastine, procarbazine, and prednisone; NOVP: Novantrone, vincristine, vinblastine, and prednisone; TMA: Tissue microarrays; WBC: White blood count; IPS: International prognostic index; FFS: Failure free survival; OS: Overall survival.

\section{Competing interest}

The authors indicated no potential conflicts of interest.

\section{Authors' contributions}

WG carried out data analysis and interpretation and wrote the manuscript. LX and BSE carried out data analysis and interpretation and performed statistical analysis. AY participated in the provision of clinical data and patient samples. KSD and CSL participated constructing the tissue microarrays. KK performed the immunohistochemical studies. LM participated in providing of patient samples, data analysis, and the writing of the manuscript. FV conceived of the study, performed data analysis and interpretation, and wrote the manuscript. Final approval of the manuscript: All the co-authors.

\section{Acknowledgements}

This work was supported by funds from the K08 Physician-Scientist Award 1 K08 CA143151-01 (NIH) (to FV) SPORE Lymphoma grant UT M.D. Anderson Cancer Center Lymphoma SPORE 1P50CA136411-01A1 (to FV). A subset of patient samples were provided with assistance from the Biospecimens Core of the Lymphoma SPORE.

* Dr Beatriz Sanchez-Espiridion collaborated in this work as a visiting scientist supported by the Department of Pathology, M.D. Anderson España and by Centro Nacional de Investigationes Oncologicas (CNIO), Madrid (Spain).

\section{Author details}

${ }^{1}$ Department of Hematopathology, Unit 72, The University of Texas MD Anderson Cancer Center, 1515 Holcombe Boulevard, Houston, TX 77030, USA. ${ }^{2}$ Biostatistics, The University of Texas MD Anderson Cancer Center, Houston, TX 77030, USA. ${ }^{3}$ Lymphoma \& Myeloma, The University of Texas MD Anderson Cancer Center, Houston, TX 77030, USA.

Received: 21 June 2012 Accepted: 1 August 2012

Published: 7 August 2012

\section{References}

1. Lowry L, Hoskin P, Linch D: Developments in the management of Hodgkin's lymphoma. Lancet 2010, 375:786-788.

2. Jona A, Younes A: Novel treatment strategies for patients with relapsed classical Hodgkin lymphoma. Blood Rev 2010, 24:233-238.

3. Aleman BM, van den Belt-Dusebout AW, Klokman WJ, Van't Veer MB, Bartelink H, van Leeuwen FE: Long-term cause-specific mortality of patients treated for Hodgkin's disease. J Clin Oncol 2003, 21:3431-3439.

4. Hsi ED: Biologic features of Hodgkin lymphoma and the development of biologic prognostic factors in Hodgkin lymphoma: tumor and microenvironment. Leuk Lymphom 2008, 49:1668-1680.
5. Diepstra A, van Imhoff GW, Karim-Kos HE, van den Berg A, te Meerman GJ, Niens M, et al: HLA class II expression by Hodgkin Reed-Sternberg cells is an independent prognostic factor in classical Hodgkin's lymphoma. J Clin Onco 2007, 25:3101-3108.

6. Sup SJ, Alemany CA, Pohlman B, Elson P, Malhi S, Thakkar S, et al: Expression of bcl-2 in classical Hodgkin's lymphoma: an independent predictor of poor outcome. J Clin Oncol 2005, 23:3773-3779.

7. Hsi ED, Sup SJ, Alemany C, Tso E, Skacel M, Elson P, et al: MAL is expressed in a subset of Hodgkin lymphoma and identifies a population of patients with poor prognosis. Am J Clin Pathol 2006, 125:776-782.

8. Rassidakis GZ, Medeiros $U$, Vassilakopoulos TP, Viviani S, Bonfante V, Nadali $G$, et al: BCL-2 expression in Hodgkin and Reed-Sternberg cells of classical Hodgkin disease predicts a poorer prognosis in patients treated with ABVD or equivalent regimens. Blood 2002, 100:3935-3941.

9. Montalban C, Garcia JF, Abraira V, Gonzalez-Camacho L, Morente MM, Bello $\mathrm{J}$, et al: Influence of biologic markers on the outcome of Hodgkin's lymphoma: a study by the Spanish Hodgkin's Lymphoma Study Group. J Clin Oncol 2004, 22:1664-1673.

10. Steidl C, Lee T, Shah SP, Farinha P, Han G, Nayar T, et al: Tumor-associated macrophages and survival in classic Hodgkin's lymphoma. N Engl J Med 2010, 362:875-885.

11. Gottesman MM, Fojo T, Bates SE: Multidrug resistance in cancer: role of ATP-dependent transporters. Nat Rev Cancer 2002, 2:48-58.

12. Allen JD, Brinkhuis RF, van Deemter L, Wijnholds J, Schinkel AH: Extensive contribution of the multidrug transporters P-glycoprotein and Mrp1 to basal drug resistance. Cancer Res 2000, 60:5761-5766.

13. van der Kolk DM, de Vries EG, van Putten WJ, Verdonck LF, Ossenkoppele GJ, Verhoef GE, et al: P-glycoprotein and multidrug resistance protein activities in relation to treatment outcome in acute myeloid leukemia. Clin Cancer Res 2000, 6:3205-3214.

14. Leith CP, Kopecky K, Chen IM, Eijdems L, Slovak ML, McConnell TS, et al: Frequency and clinical significance of the expression of the multidrug resistance proteins MDR1/P-glycoprotein, MRP1, and LRP in acute myeloid leukemia: a Southwest Oncology Group Study. Blood 1999, 94:1086-1099.

15. Singh RR, Kunkalla K, Qu C, Schlette E, Neelapu SS, Samaniego F, et al: $A B C G 2$ is a direct transcriptional target of hedgehog signaling and involved in stroma-induced drug tolerance in diffuse large B-cell lymphoma. Oncogene 2011, 30:4874-4886.

16. Deeley RG, Cole SPC: Substrate recognition and transport by multidrug resistance protein 1 (ABCC1). FEBS 2006, 580:1103-1111.

17. Steidl C, Telenius A, Shah SP, Farinha P, Barclay L, Boyle M, et al: Genomewide copy number analysis of Hodgkin Reed-Sternberg cells identifies recurrent imbalances with correlations to treatment outcome. Blood 2010, 116:418-427.

18. Kim JE, Singh RR, Cho-Vega JH, Drakos E, Davuluri Y, Khokhar FA, et al: Sonic hedgehog signaling proteins and ATP-binding cassette G2 are aberrantly expressed in diffuse large B-cell lymphoma. Mod Pathol 2009, 22:1312-1320

19. Sanchez-Espiridion B, Sanchez-Aguilera A, Montalban C, Martin C, Martinez R, Gonzalez-Carrero J, et al: A TaqMan low-density array to predict outcome in advanced Hodgkin's lymphoma using paraffin-embedded samples. Clin Cancer Res 2009, 15:1367-1375.

20. Carde P, Koscielny S, Franklin J, Axdorph U, Raemaekers J, Diehl V, et al: Early response to chemotherapy: a surrogate for final outcome of Hodgkin's disease patients that should influence initial treatment length and intensity? Ann Oncol 2002, 13(Suppl 1):86-91.

21. Miyake K, Mickley L, Litman T, Zhan Z, Robey R, Cristensen B, et al: Molecular cloning of CDNAs which are highly overexpressed in mitoxantrone-resistant cells: demonstration of homology to $A B C$ transport genes. Cancer Res 1999, 59:8-13.

\section{doi:10.1186/1756-8722-5-47}

Cite this article as: Greaves et al:: Detection of $A B C C 1$ expression in classical Hodgkin lymphoma is associated with increased risk of treatment failure using standard chemotherapy protocols. Journal of Hematology \& Oncology 2012 5:47. 